\title{
Changing Teacher Beliefs and Attitudes towards Inclusion in South Africa: Lessons from Collaborative Action Research
}

\author{
Tsediso M. Makoelle
}
University of Johannesburg, Department of Educational Psychology, Faculty of Education, Auckland Park (APK) Campus, B-Ring 417A South Africa
E-mail: tmakoelle@uj.ac.za

KEYWORDS Educational Change. Community of Enquiry. Inclusive Education. Inclusive Practices. Inclusive Learning Community

\begin{abstract}
Worldwide there is a challenge to change teacher beliefs and attitudes towards implementing full inclusive education. This paper therefore reports on a collaborative action research process that sought to change teacher beliefs and conceptions about inclusion. The study was conducted qualitatively and adopted a critical emancipatory stance. Data were collected during action research stages through collaborative action research meetings, research diaries, participant observations and interviews. The data were then analysed using both group interpretative and inductive analytical frameworks. The findings indicated, inter alia, that while change through participation is crucial, changing teacher beliefs and attitudes about inclusion requires local context-relevant practices that teachers can relate to.
\end{abstract}

\section{INTRODUCTION}

Inclusive education is the process whereby the school responds to the needs of all learners regardless of their background (Ainscow 1999; Makoelle 2013). Learners should be accommodated in matters related to teaching and learning. Rather than expect learners to adapt to the school, the school should adapt to the learners by ensuring that all their needs are met. However, the process of developing practices of inclusion often involves a change in teacher beliefs, attitudes and practices. Dyson et al. (2012) contend that inclusive practices should be developed as close to local communities as possible. Therefore the process of implementing inclusive education seems to be dependent on teacher and how well educational change (reform) is managed to benefit all learners in the school.

Change is often regarded as a complex and difficult process to initiate and implement. Because schools are places characterised by a high degree of diversity, and individuals at school relate to one another according to the school's protocol of authority or responsibility, notions of power and equity cannot be divorced from the process of change (Matthes 2013).

Change is influenced by a number of factors at the school. Increased teacher responsibility and administrative loads are a serious hindrance to the realisation of change in schools. Fullan (2001) postulates that much is expected of teach- ers, even though they receive very little support from the education authorities and the learners' parents. Teachers experience what could be termed "low morale", the phenomenon associated with low motivation among teachers. Schools are often highly politicised, which only serves to create a barrier to the effective initiation and implementation of change (Fullan 1999, 2001).

Change does not occur in a vacuum but takes place in a particular way and according to certain patterns. Change is known to be influenced by various factors such as needs, which could become a priority of the school community, as well as by clear sets of objectives and goals which the school wants to achieve. Change can be evaluated and its quality can be assessed (McCallion 1998). Some practical implications are found to be associated with change, for example the availability of resources and time.

It is important that schools guard against politically ambitious programmes of change (Fullan 2001). There are instances where the tradition of leadership in countries such as South Africa results in principals and education officials often resorting to autocratic means to impose changes on teachers (Engelbrecht and Green 2001; Weber 2007). In such cases, the system is characterised by a suppressive political ideology and change is mostly driven by a political agenda to perpetuate exclusion. Therefore, this study sort to determine how teacher beliefs 
and attitudes could be changed towards implementing inclusion. The following research question was therefore posed:

How can teacher beliefs and attitudes be changed towards implementing inclusion?

\section{The Approaches that Underpin Teacher Change at Schools}

There are many approaches to change; for example, Fullan (1999: 39) distinguishes between the complexity and the evolutionary approach. The complexity approach denotes that change is an interactive rather than a linear process. The link between cause and effect does not exist and change operates in a continuum ranging from stability to instability. The evolutionary approach, on the other hand, refers to how human beings evolve over time in relation to their interactive and cooperative behaviour.

Change is dependent on the capacity of teachers to create knowledge with the purpose of learning new ideas. Change takes place in what Fullan (1999) calls a social collaboration context. The process of social collaboration occurs within the framework of a collaboration culture; that is, the culture where all members of the school community work as a team to achieve a common purpose. Social collaboration respects diversity while building trust among the participants. It may instil anxiety among the participants but also absorb it. Knowledge is created through interactive engagement and connections. Change is an open system, subject to the contributions of the collaborating members (Fullan 1999). Spiritual, political and intellectual aspects are significant during the process of change, which could expand beyond the periphery of the school into the outside world by making connections, which is often referred to as "networking" (Ainscow et al. 2006).

In reflecting on change, Hoban (2002) argues, teachers have to apply systems thinking, which involves seeing the interrelationship between the whole and its parts. Systems thinking is in contrast to the notion of a piecemeal approach to the implementation of change, because, when it is applied, reality could be so complex and dynamic that it refutes the linear cause-effect model of educational change.

According to Hoban (2002), for teachers to understand change, they should establish a learning community (a group of persons in pur- suit of a common learning objective), which could assist teachers in drawing strategies together and challenging their beliefs to make change easier. Such a community is based on teacher co-operation and team work. Teachers should be willing to share power and authority, be independent to some extent, and be motivated by the purpose of learning together. The learning community is a collective focused on building the capacity of teachers to reflect on their teaching practices; communicate effectively among themselves, and provide the necessary inputs for the process of change (Hargreaves 2013).

The notion of how teachers change is a complex issue (Morrish 2013). Similarly, the way teachers conceptualise the notion of changing from a traditional to an inclusive teaching method is a difficult and on-going process. It is significant for teachers to take the opportunity to reflect on the proposal for change by reviewing their values and beliefs and the manner in which these values affect their daily work. Teachers should allow themselves to think on their own about change rather than having change imposed on them (Richards et al. 2001). A platform could be created for teachers to discuss and reflect on how change will be planned, implemented, monitored and controlled (Mittler 2000).

Educational change has to take teacher beliefs and their missions into consideration, if it is to be successful. Recognising teachers' beliefs elevates their motivation because they will see themselves as valuable members of the learning community (Goodson 2003).

Educational change has to involve all teachers for it to be accomplished. There must be a balance between the pressure to implement change and the support given to teachers to implement it. The relationship between changes in behaviour and changes in beliefs should be enhanced. All those involved in the process of change should own it and make valuable contributions, which will ensure success (Fullan 2001).

Educational change should be planned around the context and the prevailing local culture. It requires that all parties involved in the process of change should show a high level of commitment, acknowledging diversity and instilling respect for the opinions of others. It is important that the participants in the process of change should learn to exercise caution and patience, because change takes time to be realised. 
The notion of change is referred to as a process encompassing concepts such as beliefs, attitudes, knowledge, understanding, self-awareness and teaching practice (Richards et al. 2001). Teachers' beliefs are important because, together with their context, they shape how teachers will relate to the process of change. Such a process becomes more effective when a bottom-up rather than a top-down approach is used.

Change also works well when it is not imposed. However, education departments often implement politically driven systemic changes, ignoring what works and is best for the situation.

Teachers have to be supported in their quest for transformation and change. They have to be motivated in order for them to be committed to the process of change. Haney et al. (2002) conducted a research project on teacher motivation and their will to implement change. They discovered that any reform in education will succeed if it takes the beliefs of teachers into consideration. The research indicated that the belief teachers have about themselves influences how they conceptualise change. For example, if teachers have faith in their own professional competence, it will influence their motivation and self-efficacy profoundly, thereby raising their willingness to implement change. The theory of motivation as a system explains how the teacher's will to implement change is influenced by his/her self-efficacy and situational context.

This implies that, if the teacher regards himself/herself as competent, the school environment will be conducive to change, adequate support will be given, and the teacher will be motivated. Chances are that change will be implemented successfully.

Change cannot take place if the leadership of the school does not support it. Although change is one of the processes that occur at the school, it is often difficult to manage and control (Fullan 2004). What is being stressed here is that the leadership of the school should understand change rather than try to control it. Fullan (2004) cautions against the top-down imposition of innovative ideas on teachers by the school leadership. Similarly, leaders have to inculcate respect for the opinions and ideas of others. Leaders should understand that change is not a smooth process, but that it is characterised by what Fullan (2004) calls an implementation dip, which takes place when an envisaged plan goes awry. It is the resistance that teachers could develop to the process of change. Leaders have to note that the process of addressing resistance has to define what resistance is, as well as demonstrate a willingness to listen to those opposed to change, to try to find out why they resist change, to attempt to address their concerns, and to incorporate their inputs into the broader programme of change. Leadership should embark on what is called re-culturing, which is the development of a culture of collaboration with teachers. This includes building a network of support and maintaining good interpersonal relationships based on trust and respect between the leadership of the school and teachers. The teachers and the school leadership should engage with one another in shaping and exchanging knowledge and ideas.

\section{Change Strategies in Inclusive Education}

Engelbrecht and Green (2001) argue that, in the South African context, change is hampered by resistance from the teachers because of the oppression of and injustices meted out to teachers by the former apartheid education system. Engelbrecht and Green (2001: 33) further suggest that implementing change towards an inclusive system should begin with the principal of the school, whose vision must encapsulate what is called an "inclusive tone"-a step in the development of an inclusive learning соттиnity. Unlike in the past, he/she should eschew autocratic rule in favour of democratic and participatory leadership and inclusive management.

Most researchers in inclusive education believe that teachers implement change when they are fully involved in initiating, designing, and implementing it. Ainscow et al. (2006) indicate that they have worked with teachers collaboratively and embarked on an action research project which saw teachers become researchers in developing inclusive practices at their schools. Ainscow et al. (2006: 56) had the following to say about collaboration as a strategy to develop inclusive practices in schools:

Rather than handing practitioners a blueprint for action we sought to work collaboratively with them to explore how their context could be understood and what actions might be possible therein.

The process referred to as collaborative enquiry began with teachers and experts partic- 
ipating in a workshop to develop a common understanding about how the project should be run (Makoelle 2013). The teachers and experts established a network in which all teachers participated as part of their development plan. Joint meetings involving both practitioners and researchers were held to engage with the evidence collected. The teachers were allowed to investigate their own practice as part of the school's agenda while the researchers pursued their own research agenda; however, both worked collaboratively (Ainscow et al. 2011).

The other way of implementing inclusion is what is termed a communities of enquiry. community of enquiry usually stem from collaboration among teachers (Reason and Bradbury 2006). This is a process whereby individuals become participants in a collective community in order to probe their practice. As meanings are generally informed by their socio-historical and cultural context, this reflective process makes it possible for them to be negotiated collaboratively. The development of such a community depends to a large extent on processes of communication, meaning-making, and meaningful interaction between members of the community. Thus the process of collaboration becomes pivotal in the communicative culture of the community and results in a culture of positive practice.

The notion of communities of enquiry is crucial to the implementation of educational reform in that it offers teachers the opportunity for growth and development (Hargreaves 1997). The notion of critical friends (who view one another's work critically with the aim of improving their professional practice) is the basis on which teachers build connections as they engage in reflection and meaning-making (McTaggart 1997). The community of enquiry is also referred to as a learning community in the sense that the members are involved in a collective learning process which depends to a large extent on how well they interact, share meaning and collaborate with one another (Nind and Sheehy 2004).

This is essential for the development of an inclusive learning community as a process through which teachers develop an inclusive learning culture through collaboration and cooperation (Engelbrecht and Green 2001).

The two approaches highlighted above emphasise teacher collaboration because it has several benefits. Collaboration is often regarded as a critically important constituent of action research and therefore crucial to the process of educational change (Save the Children 2002; Somekh 2006). In the process of collaboration, triangulation becomes prominent as it allows the participants to look at concepts from a multiplicity of perspectives. Various methods could be used in this process, including those of conducting observations and interviews; harvesting statistics; producing specimen teaching plans; and preparing interview notes, questionnaires, pictures and videos.

Collaborative enquiry fosters mutual relationships between the researcher and teachers by focussing on the significance of the agenda of both the researcher and the teachers. It is from the collected data and evidence that both parties will begin to map out their respective agendas to plan change and transformation. The collected data and evidence form the core of the discussions during the processes of analysis and interpretation.

The discursive engagement is referred to as a group interpretive process as all participants are engaged as a collective in the process. The issue of different explanations and interpretations is addressed through dialogue, thus also dealing with the trustworthiness of the process.

The process of collaboration is sometimes equated with what is called voluntary change, which means the willingness to cooperate (Richardson 1998). Collaboration is characterised by a high level of teacher reflective processes. To manage change, teachers may work collaboratively with what is termed critical friends; that is, colleagues who review the data critically and reflect on the pedagogic practices of their fellow-teachers, thus sharing ideas (Mohr et al. 2004).

Reflection is usually employed to monitor the process of change (Loreman et al. 2005). This is the process whereby teachers reflect on their teaching practice in relation to the objectives they have set for themselves. Reflection could be done daily by the means of a reflection dairy, which is a record of every change that has been observed and experienced. Reflective teaching and research will change teachers' perceptions of themselves and encourage them to try new ideas, methods and approaches (Nind and Sheehy 2004). This collaborative reflection process is known as "mutual adaptation" because all the participants in the reflection process are bound to gain new ideas and therefore change (Rich- 
ardson 1998). The process is on-going and teachers could engage in it throughout the day, to reflect on, inter Changing perceptions of teaching (Hargreaves and Fullan 2000).

The reflection process described above is sometimes associated with the notion of the teacher as a learner, which indicates that, through the reflective process, teachers are engaged in a process of learning about their own practices. The reflection process is also likened to what is called images of teaching and learning that teachers construct. Briscoe (1996: 47) defines this concept as "the knowledge that teachers have about their work and their role is constructed as sensory experiences and is given meaning through reflection". This process is dominated by the process of brainstorming or meaning-making, which is important for teachers to learn from one another.

Therefore the theoretical framework for developing collaboration is based on the notion of an historic cultural approach and the belief that peer interaction is fundamental as a mediation tool (Cesar and Santos 2006). Learning is viewed as a communicative process through which those involved in the learning process negotiate meaning, construct knowledge, and allow the process of meaning exchange to shape their identity. The relationship between members in a community of practice is a symbiotic one in that members learn from one another.

\section{METHODOLOGY}

Most of the literature on teacher change and change implementation indicates that teachers embrace and implement change when they are involved in or have had a chance to participate in the initiation, planning, designing and implementation of teaching and learning processes. Most literature on initiating change in schools to develop inclusive practices also points to the significance of teacher collaboration as an appropriate approach (Fullan 1999; Engelbrecht and Green 2001; Ainscow et al. 2006; Cesar and Santos 2006; Savolainen et al. 2012; Morton et al. 2012).

The South African context provides evidence that teacher involvement is a prerequisite for change. For example, Engelbrecht and Green (2001) note that teachers in South Africa have developed a resistant attitude towards change because it was often imposed on them during the era of apartheid education. It is therefore crucial that any process of change, as Fullan (1999) maintains, take the beliefs of teachers into consideration and acknowledge that they are active participants in the process, if it is to be realised. This accounts for the importance of this study about promoting inclusion and the participation and involvement of teachers.

Teachers in South African schools find themselves in a position where they have had to implement inclusive education since its introduction in 2001 (DoE 2001). The process of change from the traditional uninclusive way of teaching to an inclusive approach prompts teachers to reflect critically on their classroom practices. The process of reflection on teaching practice was uncommon in South African schools prior to the new dispensation. Consequently, the opportunity to be action researchers afforded the participating teachers the chance to emancipate themselves from the bondage of indoctrination and the injustices of the past apartheid education ideology. This was achieved by creating an atmosphere conducive to allowing teachers to initiate processes of observation and reflection and consequently determine what was applicable in their context. This was emancipatory in the sense that none of the solutions to their problems was imposed on them.

In this study, apart from the collaborative action research project designed to enable the participating teachers to address the shortcomings of their pedagogy with respect to inclusion, the researcher decided to conduct a qualitative investigation within the theoretical schema of collaborative action research. This was a meta-research investigation of 15 teachers in a South African school. Fifteen teachers at Platinum High school (pseudonym) voluntarily took part in the project. The sample of 15 teachers was spread as follows: junior teachers (0-10 years of teaching experience); specialist teachers (10-20 years of teaching experience); and senior specialists (20 and more years of teaching experience).

Data were collected during the collaborative action research process for the two research processes, namely collaborative action research (with teachers) and qualitative meta-research (researcher). While there are many ways of collecting qualitative data, during the collaborative action-research process the research team regarded the following methods as relevant and 
appropriate: participant observation, interviews and focus-group interviews, and diaries. Because data were collected for both the collaborative action research process and for the author's meta-research, it was important to provide details of who did what before data collection techniques could be discussed. Table 1 summarises the data collection techniques used in this research.

Table: 1 Summary of research techniques

\begin{tabular}{ll}
\hline Data collection technique Who? \\
$\begin{array}{l}\text { Participant } \\
\text { observation }\end{array} \begin{array}{c}\text { Both the teachers and the researcher } \\
\text { engaged in observations. } \\
\text { Interviews } \\
\begin{array}{l}\text { The researcher interviewed the teach } \\
\text { Both the teachers and the researcher } \\
\text { kept reflection diaries. }\end{array} \\
\text { Diaries }\end{array}$ \\
\hline
\end{tabular}

The research process was a four-stage collaborative action research study consisting of the following stages: planning, observation, action, and reflection. Whenever necessary, a stage was sub-divided into phases. Table 2 gives a structural outline of each of the stages, followed by a brief summary of what happened during each stage (phase).

Two approaches were used to analyse the data: that is, an inductive analytical framework, which is the process of deriving meaning from data; and a group interpretative data-analysis approach, which is a collective interpretative system.

It is important to note that the two processes did not run parallel to each other but were interactive. In practice, the group interpretative analysis would take place at the level of engagements with teachers, but the researcher would go beyond that and embark on a meta-analysis, using an inductive analysis from a theoretical perspective. Data were interpreted in stages as the research progressed. Group interpretative meetings were held after each phase. The meetings took the form of a discussion, and the minutes were taken by the secretary of the volunteer research committee and afterwards verified by all the other members for accuracy. The interpretative discussions were chaired by a chair elected for the meeting. The discussions were facilitated by asking questions to stimulate discussion. The group would read the data, identify the main themes, assign extracts (quotations) to them, and then interpret them. Agreement on interpretations was reached through consensus. The dissenting views were discussed at length and recorded as such.

After the group interpretative processes, the researcher also attempted to make sense of all the data from his own point of view, which included observation, interviews, teacher daily reflection diaries, minutes of teachers' analysis and interpretation meetings, and the researcher's diary. The researcher used a systematic set of procedures to develop and arrive inductively at a theory about the phenomenon, a principle borrowed from grounded theory (Strauss and Corbin 1990: 24). The data were allowed data to 'talk' by deriving themes, patterns and meanings from them.

\section{RESULTS}

The data yielded several themes and were analysed in two stages in order to determine whether or not change occurred as a result of the action research process. Thus the data were analysed before and after the research process.

\section{Pre-action Research}

The data analysis indicated that there were three areas which needed to be addressed if teachers' attitudes and beliefs about inclusion were to change. The following three themes were discussed in this regard:

Table 2: Collaborative action research stages and phases

\begin{tabular}{lll}
\hline Stage & Phases & Action \\
\hline $\begin{array}{l}\text { Stage 1: Planning } \\
\text { Stage 2: Observation }\end{array}$ & $\begin{array}{l}\text { Phase 1Phase 2 } \\
\text { Phase 1Phase 2 }\end{array}$ & $\begin{array}{l}\text { PreparationIdentification (brainstorming) } \\
\text { Observation of current practiceParticipant observation } \\
\text { on how inclusive practices were used } \\
\text { Adoption of practices in the class to develop teachers' } \\
\text { skills in using them to enhance full inclusion } \\
\text { Evaluating action research as a methodologyWriting a } \\
\text { report and making recommendations }\end{array}$ \\
\hline
\end{tabular}




\section{Theme 1: Research Skills}

The teachers seemed reluctant to conduct action research, claiming that they were not skilled in doing research. For instance, one teacher stated: "We have not been trained to conduct this form of enquiry, so it is a challenge to us."

It also became apparent that teachers were not used to probing, reflecting on, and critiquing how inclusive their teaching practices were; for instance, one remarked: "We teach the way we think it would be inclusive as individual teachers, without bothering about what is going on in other classes."

\section{Theme 2: Involvement, Collaboration and Reflection of Teachers in Developing Practices}

Initially, the teachers appeared not to be participating in processes that were geared towards probing their practice; for example, one teacher postulated: "We are not involved when practices are developed; we just get guidelines from the department." The teachers were reluctant to discover alternative ways of teaching inclusively; for instance, during one of the brainstorming meetings, one remarked: "I think when people teach they follow their own philosophy about what constitutes an inclusive teaching." There was also an indication that the teachers were not used to reflecting on their practice as a collective as most of them preferred to work on their own. In this regard, one of the teachers stated: "We do not collectively look at our work; everyone does his/her work as required by subject policies."

\section{Theme 3: Influence of Past Practices, Beliefs and Attitudes}

The participating teachers believed that special needs education was still relevant as they were not trained to handle learners with 'disabilities'. For example, one of the teachers pointedly remarked that some learners do not belong in the mainstream: "We cannot teach learners with disabilities; they must go to special schools."

\section{Post-action Research}

The analysis of the data indicates that, after all the stages of action research had been com- pleted, there were noticeable changes in the attitudes and beliefs of the teachers about inclusion. These are discussed according to the preaction research themes to show whether or not change occurred.

\section{Theme1: Research Skills}

Reflecting on the action research process, the teachers seemed confident that the research skills they had acquired would ensure the sustained probing, reflecting on and critiquing of their practice. As evidence to this change, one of the teachers said: "The action research process has changed our thinking around enquiring about our practice; we are in a better position to improve our practice through a systematic enquiry."

\section{Theme 2: Involvement, Collaboration and Reflection of Teachers in Developing Practices}

The teachers seemed satisfied with the level of discussion and engagement maintained during the action research process. They indicated that they had learned from their colleagues; for example one teacher stated: "I have learned to listen and share ideas with my colleagues." Similarly, another one stressed the value of the experience by saying: "I have discovered that there could be alternative ways of doing things." The teachers regarded observation of their colleagues as informative; however, most of them felt it should have been done more frequently; for example, two of the teachers remarked (1) "I could learn a lot from colleagues but I think we should have done it more frequently." (2) "I think our conversations were open and allowed me to say what I wanted to say freely."

With regard to the process of adopting inclusive practices in class, some teachers thought the process had gone smoothly; for example, one teacher said: "I had an opportunity to start a new way of teaching successfully." But there were strong indications that the sudden change of approach affected both the teacher and the learner. Teachers indicated that the time for adopting practices was short and did not allow the learners to adjust appropriately. One teacher argued: "I think the time we got was [too] short for me and the learners to adjust fully to the newly introduced way of teaching and learning." 
With regard to reflecting on their practice, the teachers indicated that they had learned a great deal from the process and that the experience had been valuable; for example, one of them stated: "I think it is good to look at what you are doing, reflect on it and do [make] some improvement." To sustain the process over the next academic year, the teachers cited the importance of collaboration; for example, one participant said: "We must plan together a programme that will enhance collaboration among us."

Therefore, the teachers decided to establish a permanent structure that would continue this process of inquiry into their practice even after the study. To do this, the teachers had to write a letter to the principal requesting permission to establish such a committee. The functions of the committee as suggested by the teachers were to be the following:

- Call a meeting to review practice.

- Develop a programme to adopt practices to be used in the classroom.

- Call a meeting to share the experiences about the practices.

- Reflect, challenge one another's positions, and provide support to colleagues.

- Assist in collaborative planning and ensure support through class visits and joint teaching.

\section{Theme 3: Influence of Past Practices, Beliefs and Attitudes}

While it could be ambitious to claim that the beliefs of teachers had changed as a result of the action research process, it became apparent that some had adjusted their convictions about inclusion. For example, one teacher stated: "We are now aware that we can develop inclusive practices by ourselves to suit our context; we cannot cling to practices we used in the past without question."

\section{DISCUSSION}

The study was conducted to answer the research question: How can teacher beliefs and attitudes be changed towards inclusion? The findings revealed the following:

The study has confirmed that teachers do embrace change if they are involved in the modalities of the change process (Ainscow et al. 2006). Furthermore the indication is that teacher do not usually have the skills to probe, critique and reflect on their practice which is significant for the way they can change their conceptions and beliefs about how inclusive their practices are (Makoelle 2013).

The study has also confirmed that collaboration is essential for changing teacher perspectives about their practices (Makoelle 2012). This come about as a result of sharing knowledge from others which broaden their horizons in terms of changing how they think, plan and execute their practices. Further, it seems as though the reflections about practice provide an opportunity for teachers to evaluate how their beliefs and attitudes about inclusion and how it should be practiced (McTaggart 1997).

The study has demonstrated that the type of training the teachers got has a profound influence on how well they would embrace new ideas and practices. The study has demonstrated that the special need education that which was the component of past teacher training continue to influence how well teachers will be willing to change their beliefs and attitudes towards inclusion. Participating teachers lacked the skill to probe, reflect on and critique their inclusive practices.

It can therefore be concluded that, if teachers are more involved in processes of developing inclusive practices, they will collaborate, try new practices in their contexts, and will be more likely to develop a positive attitude as the result of taking ownership of the practices. It is also evident that developing a community of enquiry that is teacher driven could be helpful. It is clear that clinging to outdated notions of teaching practice is the result of lacking the opportunity to try something new.

\section{CONCLUSION}

While the study on which this paper is based was conducted on a limited scale and calls for more research, it makes a valuable contribution to the discipline of inclusion and provides a basis for changing teacher attitudes and beliefs in the current South African educational context.

\section{RECOMMENDATIONS}

Based on the findings of this study it is recommended that for teachers to change their beliefs and attitudes towards inclusion they need 
to be involved in the process of change, their voices are crucial to transformation of their practices. Furthermore the teachers need to develop the skill to probe, critique and reflect on their practices, evaluate how inclusive they are and develop new ways to be more inclusive. This could result in the shifting of beliefs and attitudes about inclusion as some practice begin to work for them and learners in the classroom.

Collaboration has been confirmed to be crucial in changing how teachers view their practice. The value of seeing how others work has an immense potential to change of teacher beliefs and attitudes about inclusion. Mutual learning is therefore crucial for teacher transformation. Therefore it suffices to recommend that collaborative teaching and learning groups be established to provide a collaboration platform for teachers.

It is evident that teacher training influences perceptions of teachers about inclusion. To change beliefs and attitudes of teachers about inclusion will require a different approach towards teacher training. Teacher training curriculum should as far as possible advocate inclusion to influence the views of aspirant teachers about inclusion

\section{REFERENCES}

Ainscow M 1999. Understanding the Development of Inclusive Schools. London: Routledge Falmer

Ainscow M, Booth T, Dyson A 2006. Improving Schools, Developing Inclusion. London: Routledge.

Ainscow M, Dyson A, Goldrick S, West M 2011. Developing Equitable Education Systems. London: Routledge Falmer.

Briscoe C 1996. The teacher as learner: Interpretations from a case study of teacher change. Journal of Curriculum Studies, 28(3): 315-329.

Cesar M, Santos N 2006. From exclusion to inclusion: Collaborative work contributions to more inclusive learning settings. European Journal of Psychology of Education, 21(3): 333-346.

Department of Education 2001. Education White Paper 6: Building An Inclusive Education and Training and System. Pretoria.

Dyson A, Kerr K, Raffo C, Wigelsworth M 2012. Developing Children's Zones for England. London: Save the Children.

Engelbrecht P, Green L 2001. Promoting Learner Development: Preventing and Working with Barriers to Learning. Pretoria: Van Schaik.

Fullan M 1999. Change Forces: The Sequel. London: Open University Press.

Fullan M 2001. The New Meaning of Educational Change. $3^{\text {rd }}$ Edition. London: Routledge Falmer.
Fullan M 2004. Leading in a Culture of Change: Personal Action Guide and Workbook. San Francisco, CA: Jossey-Bass.

Goodson IF 2003. Professional Knowledge, Professional Lives: Studies in Education and Change. Philadelphia, PA: Open University Press.

Haney JJ, Lumpe AT, Czerniak CM, Egan V 2002. From beliefs to action: The beliefs and actions of teachers implementing change. Journal of Science Teacher Education, 13(3): 171-187.

Hargreaves RE 1997. Beyond Educational Reform: Bringing Teachers Back In. Buckingham: Open University Press.

Hargreaves A 2013. Push, pull and nudge: The future of teaching and educational change. In: Xudong Zue, Kenneth Zeichner (Eds.): Preparing Teachers for the $21^{\text {st }}$ Century. Berlin, Heidelberg: Springer, pp. 217-236.

Hoban GF 2002. Teacher Learning for Educational Change: A Systems Thinking Approach. Buckingham: Open University Press.

Loreman T, Deppeler J, Harvey D 2005. Inclusive Education:A Practical Guide to Supporting Diversity in the Classroom. London: Routledge Falmer.

Makoelle TM 2012. Analysing the use of action research to develop practices of inclusion: A case of a South African school: International Journal of Sociology and Social Anthropology 3(2): 83-91

Makoelle TM 2013. Inclusive Pedagogy in Context: A South African Perspective. Germany: Lambert Academic Publishing.

Matthes A 2013. Navigating educational change: A teachers' voyage. TEACH Journal of Christian Education, 7(1): 6 .

McCallion P 1998. Achievement For All: Achieving Excellence in Schools. London: The Stationary Office.

McTaggart R 1997. Participatory Action Research. New York: State University of New York Press.

Mittler P 2000. Working towards Inclusive Education: Social Context. London: David Fulton.

Mohr MM, Roger C, Sanford B, Nicerino MA, Maclean MS, Clawson S 2004. Teacher Research for Better Schools. New York: Teacher College Press.

Morrish I 2013. Aspects of Educational Change (RLE Edu D). London: Routledge.

Morton M, Higgins N, MacArthur J, Phillips H 2012. Introduction to the Special Issue: Making Inclusive Education Happen: Ideas for Sustainable Change. International Journal of Inclusive Education. From <http://dx.doi.org/10.1080/13603116.2011. 602289> (Retrieved on November 10, 2012).

Nind M, Sheehy K 2004. Making it Happen: Inclusive Education, Learning from Each Other. Milton Keynes: Open University Press.

Reason P, Bradbury H 2006. Handbook of Action Research. London: Sage.

Richards JC, Gallo PB, Renandya W A 2001. Exploring teachers' beliefs and the process of change. PAC Journal, 1(1): 41-48.

Richardson V 1998. How teachers change. Focus on Basics, 2(c): 7-11. 
Save the Children 2002. Schools For All: Including Disabled Children in Education. London.

Savolainen H, Engelbrecht P, Nel M, Malinen O P 2012. Understanding teachers' attitudes and selfefficacy in inclusive education: Implications for pre-service and in-service teacher education. European Journal of Special Needs Education, 27(1): $51-68$.
Somekh B 2006. Action Research: A Methodology for Change and Development. Maidenhead: Open University Press.

Strauss A, Corbin J 1990. Basics of Qualitative Research: Grounded Theory Procedures and Techniques. London: Sage.

Weber E 2007. Globalization "global" development and teacher work: A research agenda. Review of Educational Research, 77(3): 279-309. 